\title{
Prognosis of vibration induced white finger: a follow up study
}

\author{
Rolf Petersen, Marc Andersen, Sigurd Mikkelsen, Steen Levin Nielsen
}

\begin{abstract}
Objectives-To follow up 102 patients with vibration induced white finger (VWF).
\end{abstract}

Methods-102 subjects with VWF were reexamined one to 13 years after the condition had first been diagnosed. Information about symptoms, occupation, vibration exposure, smoking habits, age, and the prevalence of other diseases was present in the medical records from the first examination and was collected by a questionnaire and an interview at the second examination. The decrease in systolic blood pressure in a finger during cold provocation (FSP\%) was measured in the same finger at both examinations. Results-At the second examination, $22 \%$ stated that the frequency of attacks had decreased. The improvement was most frequent in subjects with little or no exposure to vibration during the previous two years, in non-smokers, and in subjects without other circulatory diseases than VWF. $32 \%$ stated that the frequency of attacks had increased. The aggravation was most notable in smokers and subjects who also had circulatory diseases other than VWF. The number of finger phalanges that blanched on cooling averaged 15.8 at the first examination and $14 \cdot 4$ at the second examination. Working with high vibration hand held tools during the previous two years was related to an aggravation, with more finger phalanges affected at the second examination. Presence of other circulatory diseases had the same effect. In nonsmokers the number of affected finger phalanges had decreased at the second examination. The FSP\% had increased (improvement) in $43 \%$, decreased (aggravation) in 12\%, and was unchanged in $45 \%$. The increase in FSP\% was more pronounced in the older than in the younger subjects. The decrease of FSP\% was more frequent among the younger subjects and subjects with a short follow up.

Conclusion-As the FSP\% in nearly half of the subjects had improved, it is concluded that VWF has a good prognosis in patients with mainly moderate to severe VWF after one to 13 years of observation. The improvement in FSP\%, however, was not reflected in the subjective experience of the development of attacks of VWF. Continued work with high vibra- tion hand held tools, smoking, other circulatory diseases, and low age at the time of diagnosis had an unfavourable influence on the prognosis.

\section{(Occup Environ Med 1995;52:110-115)}

\section{Keywords: vibration induced white finger; prognosis}

Vibration induced white finger (VWF) is Raynaud's phenomenon induced by long lasting exposure of the hands to vibration. ${ }^{1}$ Previous investigations have shown variable results with respect to the prognosis of VWF. Several studies have shown that the symptoms decrease if the exposure is stopped or reduced,,$^{28}$ and that they decrease with the number of years without exposure. ${ }^{2457}$ Other studies report that the symptoms are unchanged or even aggravated despite finishing exposure. ${ }^{9} 13$

In two previous investigations the prognosis for VWF was evaluated objectively by a cold provocation test. One study measured the decrease in the systolic blood pressure of a finger during cold provocation (FSP\%). This response improved after the end or reduction of exposure. ${ }^{8}$ The other study measured the rewarming time of the fingers after cold provocation. This response remained unchanged after the end of exposure. ${ }^{13}$ The follow up times were five years, and three to six years, and the number of subjects examined was 12 and 24 , respectively.

Our study reports results on the prognosis for mainly moderate to severe VWF in 102 subjects with a follow up time from one to 13 years. The prognosis was measured as the change from the first to the second examination for the subjective evaluation of the frequency of attacks of VWF, for the number of finger phalanges attacked by VWF, and for the change in $\mathrm{FSP} \%$.

\section{Subjects and methods}

The study base consisted of 318 subjects who from 1978 to 1990 were examined for VWF in connection with an application for compensation for VWF as an occupational disease. All the subjects had previously been examined by one of us (SLN). Out of 318 subjects 15 had died, four could not be identified, and 87 did not have VWF. Also, several subjects were excluded: subjects who were $>65$ years old on August $1,1990(\mathbf{n}=21)$, subjects who lived outside Zealand $(n=27)$, and chosen at 
random a part of those who were examined in 1988 and $1989(n=32)$. The resulting study group consisted of 132 subjects.

Of the 132 subjects $40 \%$ had been employed in the metal industry and had mostly used small chipping hammers and angle grinders, $35 \%$ had been employed in the building industry and had mostly used hammer drills and small and big chipping hammers, and $25 \%$ had been employed in other trades and had used all sorts of vibrating hand held tools. Vibration induced white finger was diagnosed on the basis of a characteristic medical history of cold provoked episodes of proximal well demarcated blanching of fingers. The symptoms should have appeared after the subject had been exposed to extensive vibration in hands and arms and there should be no other causes of Raynaud's phenomenon.

Out of 132 invited, $102(77 \%)$ participated in the re-examination (second examination). The mean age at the first examination was 44.9 (range 21-64) years and at the second examination $50 \cdot 2$ (range 27-65) years. The difference of 5.3 years corresponds to the mean number of years between the first and second examination.

For each of the subjects, the medical records from the first examination contained data on occupation, exposure to vibration, number of finger phalanges affected by VWF, and FSP\%. At the second examination, the subjects hatched the areas affected by VWF in a drawing of the hands, completed a questionnaire, and were interviewed about occupation, changes in frequency of attacks, amount of work with vibrating tools in the follow up period, tobacco consumption, and the presence of other diseases. In all the 102 subjects, FSP\% was measured again in the same finger examined at the first examination. The second examination was conducted from December 1990 to March 1991.

At both examinations the cold provocation test was performed with the subject wrapped in a cooling carpet perfused by water at $8-12^{\circ} \mathrm{C}$. The FSP was measured by a strain gauge in the distal finger phalanx of the test finger after thermostatting the middle phalanx for five minutes of ischaemia, first at $30^{\circ} \mathrm{C}$ and then at $10^{\circ} \mathrm{C}$. The thumb of the same hand was used as an uncooled control. The FSP at $10^{\circ} \mathrm{C}$ was expressed as a percentage of FSP at $30^{\circ} \mathrm{C}$ corrected for the change in the arterial blood pressure in the control finger during the examination. ${ }^{14}$

The measurements at the first and second examination were performed by the same method with a strain gauge plethysmograph with a cooling unit. The same apparatus (SP2, Medimatic, Copenhagen) was used for all subjects at the second examination, and until 1988 for all subjects at the first examination. From 1988 the first examination was performed with a similar new apparatus (Digimatic 2000, Medimatic, Copenhagen).

At both the first and second examinations, an $\mathrm{FSP} \%$ of $<31 \%$ was considered to reflect a closure of the arteries in the test finger. On the basis of previous investigations, the lower limit for an abnormal FSP\% was set at $63 \% . .^{15}$ The study subjects were divided into three groups: FSP $\% \leqslant 30 \%, 31-63 \%$, and $>63 \%$.

All participants gave informed consent to the examination. The study was approved by the local ethics committee.

\section{STATISTICAL ANALYSES}

The response variables in the analysis of changes from the first to the second examination were the subjects' own evaluation of changes in the frequency of attacks of white fingers, the change in number of affected finger phalanges, and the change in FSP\% in the three groups $\leqslant 30 \%, 31-63 \%$, and $>63 \%$.

We analysed whether various independent variables were related to an aggravation or to an improvement in the dependent variables. Aggravation of the frequency of attacks was analysed $v$ an unchanged or improved condition, and improvement was analysed $v$ an unchanged or aggravated condition.

An aggravation or an improvement of the fingers affected by Raynaud's phenomenon was defined as an increase or a fall by more than five finger phalanges from the first to the second examination. In the analyses of aggravation, only subjects with a potential for aggravation were included. This means that subjects with more than 23 affected finger phalanges at the first examination were excluded as the total number of finger phalanges is 28 . Similarly, subjects with less than five affected finger phalanges at the first examination were excluded from the analyses of improvement as they could not improve according to our definition of improvement.

Aggravation of FSP\% was defined by a change from a group with a higher FSP\% to a group with a lower FSP\%. Improvement was defined as a similar change in the opposite direction. In the analyses of changes in FSP\%, only subjects with a potential for an aggravation or an improvement were included. Thus, subjects with an $\mathrm{FSP} \% \leqslant 30 \%$ at the first examination were excluded from the analyses of aggravation, and subjects with $\mathrm{FSP} \%>$ $63 \%$ at the first examination were excluded from the analyses of improvement.

The following independent variables that had a possible influence on changes in the condition from the first to the second examination were examined: use of vibrating tools during the past two years before the second examination; use of vibrating tools between the first and the second examination; age at the first examination; the number of years between the two examinations; tobacco smoking at the second examination, and presence at the second examination of other circulatory diseases (hypertension, heart disease, intermittent claudication, including one subject with diabetes mellitus and one subject treated with a $\beta$ blocker). The use of vibrating tools in the past two years before the second examination was classified by the highest level of acceleration of the three most frequently used tools. The following acceleration classes were used: $<3 \mathrm{~m} / \mathrm{s}^{2}, \quad 3-10 \mathrm{~m} / \mathrm{s}^{2},>10 \mathrm{~m} / \mathrm{s}^{2} .^{16}$ The 
Table 1 Reported change in the frequency of attacks of Raynaud's phenomenon from the first to the second examination

\begin{tabular}{lc}
\hline Frequency of attacks & $n(\%)$ \\
\hline Much increased & $16(15 \cdot 7)$ \\
Somewhat increased & $17(16 \cdot 7)$ \\
Unchanged & $47(46 \cdot 1)$ \\
Somewhat decreased & $6(5 \cdot 9)$ \\
Much decreased & $13(12 \cdot 7)$ \\
No attacks since 1st examination & $4(2 \cdot 9)$ \\
Total & $102(100)$ \\
\hline
\end{tabular}

Table 2 Distribution of the number of finger phalanges affected by Raynaud's phenomenon at the first examination (by changes of more than five phalanges at the second examination)

\begin{tabular}{llccccc}
\hline & $0-5$ & $6-10$ & $11-15$ & $16-22$ & $23-28$ & Total \\
\hline Improvement & - & 1 & 4 & 5 & 17 & 27 \\
Unchanged & 3 & 16 & 11 & 12 & 11 & 53 \\
Aggravated & 1 & 8 & 4 & 3 & -12 & 16 \\
Total & 4 & 25 & 19 & 20 & 28 & 96 \\
\hline
\end{tabular}

In six subjects information was missing about number of finger phalanges affected by Raynaud's phenomenon at the first examination. other variables were dichotomous (yes or no) or continuous variables and were treated as such in the analyses.

The effects of these variables on the dependent variables were examined in a logistic regression analyses. Age at the first examination, number of years between the two examinations, and condition at the first examination were included in all models. The effects of the other variables were examined by the forward selection principle: the model with these three fixed variables was expanded stepwise with the most significant of the remaining variables. Only variables with a significance of $<5 \%$ were included. We report the results for a common final model for all dependent variables. The model includes the three fixed variables and variables with a significant effect on at least one of the dependent variables.

\section{Results}

Table 1 shows how the study subjects judged the frequency of attacks of white fingers at the second examination relative to the first examination. Thirty three $(32 \%)$ found that the frequency of attacks had increased, $47(46 \%)$ that it was unchanged, and $23(22 \%)$ that it had decreased.

Table 2 shows the changes in the number of finger phalanges affected by attacks of Raynaud's phenomenon from the first to the
Table 3 Distribution of FSP\% at the first and second examinations

\begin{tabular}{lcccc}
\hline \multirow{2}{*}{$\begin{array}{l}\text { FSP\% at } \\
\text { 1st examination }\end{array}$} & $\leqslant 30$ & $31-63$ & $>63$ & Total \\
\cline { 2 - 5 } & \multicolumn{3}{l}{ FSP 2 at examination } \\
\hline 30 & 25 & 14 & 22 & 61 \\
$31-63$ & 3 & 3 & 8 & 14 \\
$>63$ & 3 & 6 & 18 & 27 \\
Total & 31 & 23 & 48 & 102 \\
\hline
\end{tabular}

second examination. In $53(55 \%)$ the number of affected finger phalanges was unchanged, in $27(28 \%)$ it was lower, and in $16(17 \%)$ it was higher at the second examination. In six subjects information was missing about the number of affected finger phalanges at the first examination.

Table 3 gives the distribution of FSP\% at the first and second examination. The FSP\% was unchanged in 46 subjects $(45 \%)$, had increased in 44 subjects $(43 \%)$, and decreased in 12 subjects $(12 \%)$.

Table 4 lists the results of the logistic regression analyses of the models with improvement in the dependent variable from the first to the second examination. The results in table 4 are based on the number of subjects with a potential for improvement: all of the 102 subjects could improve with respect to frequency of attacks, 92 subjects could improve with respect to the number of phalanges affected by VWF, and 75 subjects could improve with respect to FSP\%. The frequency of attacks had decreased significantly in subjects who had not worked with high vibration tools during the past two years before the second examination, in subjects without other circulatory diseases, and in non-smokers. In non-smokers the number of affected finger phalanges had decreased. An increase in FSP\% was positively associated with age at the first examination - that is, the improvement was more frequent among the older subjects. There was no significant correlation between an inciease in FSP\% and exposure to vibrating tools during the past two years before the second examination, smoking, or the presence of other circulatory diseases.

Table 5 shows the corresponding results for an aggravation of the three dependent variables. The results are based on the number of subjects with a potential for aggravation: all of the 102 subjects could experience an increased frequency of attacks, 68 subjects

Table 4 Relations between improvement of the three dependent variables and independent variables: final models of logistic regression analyses ( $P<0.05$ for $O R$ emphasised)

\begin{tabular}{|c|c|c|c|}
\hline Independent variables & $\begin{array}{l}\text { Frequency } \\
\text { of attacks } \\
\text { OR }(95 \% \text { CI) }\end{array}$ & $\begin{array}{l}\text { Number of finger } \\
\text { phalanges affected } \\
\text { OR }(95 \% \text { CI) }\end{array}$ & $\begin{array}{l}F S P \% \\
\text { OR }(95 \% C I)\end{array}$ \\
\hline $\begin{array}{l}\text { Age at } 1 \text { st examination }{ }^{\star} \\
\text { Years between } 1 \text { st and } 2 \text { nd examination }{ }^{\star} \\
\text { Condition at } 1 \text { st examination } \\
\text { Vibration tools within the past } 2 \mathrm{y} \text { : }\end{array}$ & $\begin{array}{l}0.97(0.91-1.03) \\
1.21(0.99-1.47) \\
0.31(0.08-1.23) \dagger\end{array}$ & $\begin{array}{l}1.00(0.95-1.06) \\
1.10(0.90-1.33) \\
6.57(1.99-21.7) \dagger\end{array}$ & $\begin{array}{l}1.06(1.00-1.12) \\
1.18(0.99-1.40) \\
1.08(0.29-3.99) \ddagger\end{array}$ \\
\hline $\begin{array}{l}\quad 3-10 \mathrm{~m} / \mathrm{s}^{2} \S \\
>10 \mathrm{~m} / \mathrm{s}^{2 q} \\
\text { Other circulatory diseases } \| \\
\text { Smoking at the 2nd examination } \star\end{array}$ & $\begin{array}{l}0.74(0.16-3.40) \\
0.09(0.01-0.99) \\
0.08(0.01-0.85) \\
0.23(0.06-0.89)\end{array}$ & $\begin{array}{l}2 \cdot 22(0 \cdot 60-8 \cdot 23) \\
0.63(0 \cdot 14-2 \cdot 81) \\
0 \cdot 73(0 \cdot 15-3 \cdot 41) \\
0.33(0 \cdot 10-0.97)\end{array}$ & $\begin{array}{l}2.88(0 \cdot 77-10 \cdot 7) \\
1.72(0.42-7 \cdot 07) \\
1.45(0 \cdot 39-5 \cdot 43) \\
0.92(0 \cdot 30-2 \cdot 82)\end{array}$ \\
\hline
\end{tabular}

${ }^{*}{ }^{\star}$ ORs $=\mathrm{OR} / \mathrm{y} ;$ t0 $=\leqslant 16$ finger phalanges, $1=>16$ finger phalanges; $\neq 0=\mathrm{FSP} \% \leqslant 30 \%, 1=30 \%<\mathrm{FSP} \% \leqslant 62 \%$ $\$ 0=<3 \mathrm{~m} / \mathrm{s}^{2}, 1=3-10 \mathrm{~m} / \mathrm{s}^{2} ; \eta 0=<3 \mathrm{~m} / \mathrm{s}^{2}, 1=>10 \mathrm{~m} / \mathrm{s}^{2} ; \| 0=$ not present, $1=$ present; $\star \star 0=$ non-smoker, $1=$ smoker. 
Table 5 Relations between aggravation of the three dependent variables and independent variables: final models of logistic regression analyses ( $P<0.05$ for $O R$ emphasised)

\begin{tabular}{|c|c|c|c|}
\hline Independent variables & $\begin{array}{l}\text { Frequency } \\
\text { of attacks } \\
\text { OR }(95 \% \text { CI })\end{array}$ & $\begin{array}{l}\text { Number of finger } \\
\text { phalanges affected } \\
\text { OR }(95 \% \text { CI) }\end{array}$ & $\begin{array}{l}\text { FSP\% } \\
\text { OR }(95 \% \text { CI })\end{array}$ \\
\hline $\begin{array}{l}\text { Age at } 1 \text { st examination }{ }^{\star} \\
\text { Years between } 1 \text { st and } 2 \text { nd examination }{ }^{\star} \\
\text { Condition at } 1 \text { st examination } \\
\text { Vibration tools within the past } 2 \text { y: }\end{array}$ & $\begin{array}{l}1.04(0.98-1.10) \\
0.95(0.79-1.15) \\
2.09(0.69-6.31) \dagger\end{array}$ & $\begin{array}{l}0.99(0.91-1.08) \\
0.78(0.59-1.02) \\
0.27(0.04-1.95) \dagger\end{array}$ & $\begin{array}{l}0.79(0.65-0.95) \\
0.61(0.39-0.95) \\
0.57(0.06-5.41) \ddagger\end{array}$ \\
\hline $\begin{array}{l}3-10 \mathrm{~m} / \mathrm{s}^{2} \S \\
>10 \mathrm{~m} / \mathrm{s}^{2 \mathrm{q}} \\
\text { Other circulatory diseases } \| \\
\text { Smoking at the 2nd examination }{ }^{\star \star}\end{array}$ & $\begin{array}{c}2 \cdot 95(0 \cdot 68-12 \cdot 8) \\
3 \cdot 30(0 \cdot 84-12 \cdot 9) \\
10 \cdot 1(2 \cdot 12-48 \cdot 3) \\
13 \cdot 1(2 \cdot 58-66 \cdot 8)\end{array}$ & $\begin{array}{l}3 \cdot 74(0 \cdot 40-35 \cdot 4) \\
48 \cdot 0(5 \cdot 70-404) \\
10 \cdot 7(1 \cdot 25-91 \cdot 6) \\
2 \cdot 32(0 \cdot 44-12 \cdot 4)\end{array}$ & $\begin{array}{l}0.01(0 \cdot 00-0.48) \\
0.03(0 \cdot 00-0.69) \\
0 \cdot 12(0.00-4.63) \\
1 \cdot 24(0 \cdot 12-13 \cdot 3)\end{array}$ \\
\hline
\end{tabular}

could have an increased number of phalanges affected by VWF, and in 41 subjects FSP\% could deteriorate. Smokers and subjects with other circulatory diseases experienced an increase in frequency of attacks. In subjects who had worked with high vibration tools during the past two years before the second examination, the number of affected finger phalanges had increased. The same was found in subjects with other circulatory diseases. A decrease in FSP\% was negatively associated with age at the first examination, and the number of years between the first and second examination-that is, aggravation was more frequent among the younger subjects and subjects with a short follow up. Somewhat surprisingly, we found a fall in FSP\% in more subjects with little or no exposure (acceleration $<3 \mathrm{~m} / \mathrm{s}^{2}$ ) during the past two years before the second examination than in subjects with a higher degree of exposure to vibration. Although significant, it should be noticed that these results are based on small numbers: 10 out of 21 in the low, one out of nine in the middle, and one out of 11 in the high exposure group had aggravation of FSP\%.

\section{Discussion}

Out of the 132 subjects with VWF in the study group, $102(77 \%)$ participated. There was no significant difference between the participants and the non-participants in age, number of years since first examination, occupation, and severity of VWF at the first examination. So, there is no indication of selection bias in the study.

The results of our study indicate the prognosis for the more advanced stages of VWF. On the basis of data recorded at the first examination our subjects were classified according to the Taylor-Palmear classification $^{17}$ : $6 \%$ were considered to have been in stage I, $14 \%$ in stage II, and $80 \%$ in stages IIIIV. Cross sectional studies on subjects engaged in active employment with exposure to vibration have reported considerably larger proportions of VWF in stages I and II. ${ }^{18} 19$ The participants in our study had applied for compensation for VWF as an occupational disease. Therefore, it is not surprising that they had more severe VWF than found in cross sectional studies of subjects exposed to vibration.

The data on changes in the frequency of attacks were collected by questionnaire and interview and were based on the memory of the participants about the frequency of attacks at the first examination compared with the second examination. It was possible to evaluate the validity of these answers for 89 of the participants by comparison with the statements in the medical records from the first examination about daily, weekly, or monthly attacks during the winter. Similar information was collected at the second examination. All the subjects who thought that their symptoms improved had stated a lower frequency of symptoms at the second than at the first examination. Subjects who thought that their condition was unchanged or aggravated had a tendency to find the development of their condition worse than indicated by the recorded information about the frequency of attacks.

Information about the number of finger phalanges affected by VWF at the first examination was available in the medical records from the first examination. The subject's memory of the previous condition therefore plays no part. Data on the condition at the second examination were collected by questionnaire and interview. Consequently, the changes in the number of affected finger phalanges are considered to be a more reliable estimate of the changes in the condition from the first to the second examination than the information about the changes in the frequency of attacks.

The method of measuring FSP\% has been evaluated in previous investigations. Two studies have found almost the same sensitivity (about 0.90 ) and specificity (about 0.80 ) of a fall in FSP\% to zero. ${ }^{19} 20$ The SD of the difference between double determinations of FSP\% measured at intervals of four to 10 minutes at $15^{\circ} \mathrm{C}$ and $6^{\circ} \mathrm{C}$ in subjects exposed to vibration has been found to be $6-8 \% .^{21}$ There are no reports in the scientific literature on the day to day variation of measurements. A day to day variation will only influence our results if the variation differs between the groups compared in the study. It is not possible to control for such an influence in our study.

The measurements were performed with the same type of apparatus at the first and second examination. At the second examination all measurements were done by one experienced laboratory technician. This same laboratory technician had also performed many of 
the measurements at the first examination. For these reasons it seems unlikely that differences in the results of FSP\% at the first and second examination could be due to differences in measuring technique.

At the second examination all subjects were asked if they had had an attack of VWF previously the same day as a refractory period after an attack could possibly influence the results of the FSP\%. ${ }^{14}$ In our study, however, the change in FSP\% was not dependent on any previous attack of VWF on the same day. Seasonal variation might also influence the results. ${ }^{22}$ The time of the year of the first examination had no influence on changes in FSP\%.

Our results agreed with previous investigations that showed that symptoms of VWF had a tendency to improve after a reduction in the exposure to hand-arm vibration, ${ }^{2-8}$ and conversely to aggravate in subjects with an unchanged or increased exposure to vibration during the follow up period. ${ }^{245713}$

We found a significant reduction in the frequency of attacks in subjects who had not used vibrating tools or only tools with an acceleration of $<3 \mathrm{~m} / \mathrm{s}^{2}$ during the past two years before the second examination, and an increase in the frequency of attacks in subjects who had used tools with an acceleration of $>3 \mathrm{~m} / \mathrm{s}^{2}$.

The relation between smoking and changes in VWF has been reported only by Ekenvall and Carlsson. ${ }^{7}$ They found fewer smokers among those who had experienced an improvement and more smokers among those who had experienced an aggravation. The difference was not significant. In our investigation we found a significant decrease in the frequency of attacks among non-smokers, and an increased frequency of attacks among smokers.

The influence of other circulatory diseases on the prognosis of VWF has not been reported previously. In our investigation, subjects with circulatory diseases other than VWF had a significant increase in the frequency of attacks. This finding could not be explained by treatment with medicine. Only one of the participants took $\beta$ blockers.

The number of finger phalanges affected by VWF has not previously been used as an independent measure of severity. We found that the change in the number of finger phalanges affected by VWF was related to the level of vibration of the tool used. The number increased in those who had had a large exposure to vibration during the past two years before the second examination, and conversely, it fell in those who had had a low exposure. It increased in smokers and subjects with other circulatory diseases, and fell in non-smokers and subjects without other circulatory diseases.

Two previous follow up studies have evaluated the changes in FSP\%. Ekenvall and Carlsson, however, did not report the relation between changes in FSP\% and changes in exposure to vibration during the follow up period. ${ }^{7}$ They reported only how the subjectively experienced change was related to the change in $\mathrm{FSP} \%$. In subjects who thought that their symptoms were improved or unchanged, no certain change in FSP $\%$ was found. In subjects who thought that their condition was aggravated, FSP\% had decreased. We found no relation between the subjective evaluation of the change in frequency of attacks and the change in FSP\%.

In a five year follow up study Olsen and Nielsen found that FSP\% had increased in nine out of 12 subjects with VWF who had stopped using vibrating tools or whose exposure to vibration had been reduced. ${ }^{8}$

Bovenzi et al found an aggravation of finger rewarming time in 13 subjects with continued exposure to high vibrations during a six year follow up period. They found no improvement in finger rewarming time among 24 subjects with VWF followed up for three to six years with no exposure.

We could find no relation between an increase in FSP\% and the exposure variables. Surprisingly, a fall in FSP\% was found more frequently among subjects in the category with the lowest exposure to vibration compared with either of the two higher categories (table 5). These two categories also tended to have a greater increase in FSP\% than the lower exposure group, but this tendency was far from significant (table 4). The data on decreases in FSP\% were based on rather small numbers. Only one subject in each of the two groups with the highest exposure had a fall in FSP\%. The findings on a relation between a fall in FSP\% and exposure to vibration should therefore be treated with caution.

The FSP\% increased with the number of years between the first and the second examination and decreased the shorter the follow up period. This beneficial effect of the length of the follow up period could reflect an effect of reduced exposure to vibration, as generally such a reduction had taken place in the participants during the follow up period. The sensitivity of our exposure variables, however, may have been insufficient to distinguish this effect from the effect of the follow up time.

The increase in FSP\% in the subjects who were oldest at the first examination and the fall in those who were youngest can be explained by a biological variation in sensitivity that probably makes younger subjects with VWF more sensitive to cooling than older subjects.

\section{Conclusion}

The improvement in FSP\% in nearly half of the subjects indicates a good prognosis for patients with mainly moderate to severe VWF after one to 13 years of observation. The improvement in FSP\%, however, was not reflected in the subjective experience of the development of attacks of VWF. The reported frequency of attacks did not decrease and the recorded number of affected finger phalanges decreased only a little during the observation period. The subjective outcome variables may be less reliable than the FSP\%. Continued work with high vibration hand held tools, smoking, other circulatory diseases, and low age at the time of diagnosis had an unfavourable influence on the prognosis. 
The study has been supported by grants from the Danish Working Environment Fund.

1 Greenstein D, Kent PJ, Wilkinson D, Kester RC. Raynaud's phenomenon of occupational origin. $f$ Hand Surg $[B r] 1991 ; 16: 370-7$

2 Stewart AM, Goda DF. Vibration syndrome. $B r f$ Ind Med 1970;27:19-27.

3 Pyykkö I, Sairanen E, Korhonen O, Färkkilä $M$, Hyvärinen J. A decrease in the prevalence and severity of vibration-induced white fingers among lumberjacks in Finland. Scand $f$ Work Environ Health 1978;4: 246-54.

4 Futatsuka $M$, Ueno T, Sakurai T. Follow-up study of vibration induced white finger in chain saw operators. $B r$ vilnd Med 1985;42:267-71

5 Futatsuka $M$, Ueno T. A follow-up study of vibrationinduced white finger due to chain-saw operation. Scand $\mathcal{F}$ Work Environ Health 1986;12:304-6.

6 Pyykkö I, Korhonen O, Färkkilä M, Starck J, Aatola S, Jäntti V. Vibration syndrome among Finnish forest workers, a follow-up from 1972 to 1983 . Scand $\mathcal{F}$ Work Environ Health 1986;12:307-12.

7 Ekenvall L, Carlsson A. Vibration white finger: a follow up study. $\mathrm{Br}$ F Ind Med 1987;44:476-8.

8 Olsen N, Nielsen SL. Vasoconstrictor response to cold in forestry workers: a prospective study. $\mathrm{Br} \mathcal{F}$ Ind Med 1988;45:39-42.

9 Agate JN. An outbreak of cases of Raynauds's phenomenon of occupational origin. Br f Ind Med 1949;6:144-63.

10 Jepson RP. Raynauds's phenomenon in workers working with vibratory tools. $\mathrm{Br} \mathcal{F}$ Ind Med 1954;11:180-5.

11 Taylor W, Wasserman D, Behrens V, Reynolds D Samueloff $S$. Effect of the air hammer on the hands of stonecutters. The limestone quarries of Bedford, Indiana, revisited. $B r \mathcal{F}$ Ind Med 1984;41:289-95.
12 Dandanell $\mathrm{R}$, Engström $\mathrm{K}$, Magnusson L, Ottersten $\mathrm{S}$. Exposure conditions and Raynauds's phenomenon among riveters in the aircraft industry-a follow up study. In: Proceedings of the 6th International Conference on Hand-Arm Vibration. Bonn: Hauptuerbrand-derBewerblichen-Berufsgenossenschaften, 1992:387-93.

13 Bovenzi M, Franzinelli A, Scattoni L, Vannuccini L. Hand-arm vibration syndrome among travertine workers: a

14 Nielsen SL. Raynaud's phenomena and finger systolic pressure during cooling. Scand $\mathcal{f}$ Clin Lab Invest 1978;38:765-70.

15 Nielsen SL, Sorensen CJ, Olsen N. Thermostated measurement of systolic blood pressure on cooled fingers. Scand f Clin Lab Invest 1980;40:683-7.

16 Gemme G, Ekenvall L, Hansson J-H, Lidström I-M. Skadlig inverkan ansson J-H, Lidström I-M. en försäkringsmedicinsk bedömningsmodell (A medicolegal model for the evaluation of harmful influence from hand-arm vibration). Arbete och Hälsa 1986;2:14.

17 Taylor W, Palmear PL, eds. Vibration white finger in industry. London: Academic Press, 1975.

18 NIOSH. Vibration syndrome. Washington: NIOSH, 1983. (DHHS (NIOSH) Publ No 83-110.)

19 Olsen N, Nielsen SL, Voss P. Cold response of digital arteries in chain saw operators. Br F Ind Med 1982;39: 82-8.

20 Olsen N, Nielsen SL. Diagnosis of Raynaud's phenomenon in quarrymen's traumatic vasospastic disease. Scand ₹ Work Environ Health 1979;5:249-56.

21 Olsen N. Vibration-induced white finger-physiological and clinical aspects. Copenhagen: Laegeforeningens forlag, 1988:18.

22 Ekenvall L, Lindblad LE. Vibration white finger and digital systolic pressure during cooling. $\mathrm{Br}$ f Ind Med 1986; 43:280-3. 